\title{
NEABs e a Proposição de Educação para as Relações Étnico-raciais
}

\author{
ROZA, Isis Silva ${ }^{1}$ \\ ROZA, Luciano Magela ${ }^{2}$
}

\section{RESUMO}

O artigo objetiva apresentar e discutir como os Núcleos de Estudos AfroBrasileiros estão se configurando como espaços formativos estratégicos para o desenvolvimento de propostas orientadas para reeducação das relações étnicoraciais. $O$ artigo estrutura-se em 3 partes. A primeira apresenta o contexto de ampliação dos NEABs. Para tanto, é elencado um conjunto de iniciativas de combate ao racismo, que foram implementadas a partir das primeiras décadas do século XXI. A segunda parte é dedicada à compreensão da articulação entre os NEABs, a Associação Brasileira de Pesquisadores Negros - ABPN e o Consórcio de NEABs - CONNEABs, assim como a caracterização dos núcleos. A terceira parte dedica-se a discussão sobre as contribuições dos Núcleos de Estudos Afro-Brasileiros para as ações orientadas para a reeducação das relações étnico-raciais. Um conjunto de fragmentos de entrevistas de intelectuais negras e negros envolvidas(os) nas atividades dos NEABs é evidenciado.

\section{Ações Afirmativas. Núcleo de Estudos Afro-Brasileiros. Educação. Relações étnico-raciais.}

\section{Afro-Brazilian studies nucleus and the education proposition por ethnic-racial relations}

\section{ABSTRACT}

This article aims to present and discuss how the Afro-Brazilian Studies Centers are configuring themselves as strategic training spaces for the development of proposals aimed at re-education of ethnic-racial relations. The article is structured in 3 parts. The first presents the context for the expansion of NEABs. To this end, a set of initiatives to combat racism is listed, which were implemented from the first decades of the 21st century. The second part is dedicated to understanding the articulation between the NEABs, the Brazilian Association of Black Researchers - ABPN and the NEABs Consortium - CONNEABs, as well as the

\footnotetext{
${ }^{1}$ Doutoranda em Educação pela Universidade Federal de Minas Gerais. Mestre em Serviço Social pela Universidade Federal de Juiz de Fora. Professora do Departamento de Serviço Social - DESSO da Universidade Federal de Ouro Preto. Email: isissroza@gmail.com. Lattes: http://lattes.cnpq.br/3757204728618598. Orcid: https://orcid.org/0000-0002-4188-7627.

${ }^{2}$ Mestre e Doutor em Educação pela UFMG. Professor Adjunto na Universidade Federal de Ouro Preto (UFOP). Email: lucianoroza@gmail.com. Lattes:

http://lattes.cnpq.br/4380634373591400. Orcid: https://orcid.org/0000-0002-3505-2607.
}

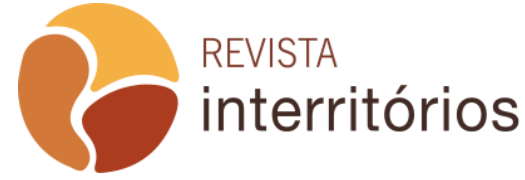


characterization of the nuclei. The third part is dedicated to the discussion about the contributions of the Afro-Brazilian Studies Centers to actions oriented towards the re-education of ethnic-racial relations. A set of fragments of interviews by black and black intellectuals involved in the activities of the NEABs is evidenced.

\section{Affirmative Actions. Afro-Brazilian Studies Center. Education. Ethnic-racial relations.}

\section{NEABs y la proposición de educación para las relaciones étnico-raciales}

\section{RESUMEN}

El artículo tiene como objetivo presentar y discutir cómo los "Núcleos de Estudos Afro-Brasileiros" se configuran como espacios de formación estratégicos para el desarrollo de propuestas orientadas a reeducación de las relaciones étnicoraciales. El artículo está estructurado en 3 partes. La primera presenta el contexto de expansión de los NEAB. De esa manera, se enumera un conjunto de iniciativas para combatir el racismo, que se implementaron desde las primeras décadas del siglo XXI. La segunda parte está dedicada a comprender la articulación entre los NEAB, la "Associação Brasileira de Investigadores Negros" - ABPN y el "Consórcio NEABs - CONNEABs", así como la caracterización de los núcleos. La tercera parte está dedicada a la discusión sobre las contribuciones de los "Núcleos de Estudos Afro-Brasileiros" a las acciones orientadas a la reeducación de las relaciones étnico-raciales. Se destaca un conjunto de fragmentos de entrevistas de intelectuales negras y negros involucrados en las actividades de los NEAB.

\section{Acciones afirmativas. Núcleo de Estudos Afro-Brasileiros. Educación. Relaciones étnico-raciales.}

\section{NEAB e la proposta di educazione per le relazioni etnico-razziali}

\section{SOMMARIO}

L'articolo si propone di presentare e discutere come i "Nuclei di studi afrobrasiliani" si configurano come spazi strategici di formazione per lo sviluppo di proposte volte alla rieducazione delle relazioni etnico-razziali. L'articolo è strutturato in 3 parti. La prima presenta il contesto di espansione dei NEAB. In questo modo vengono elencate una serie di iniziative per combattere il razzismo, che sono state attuate sin dai primi decenni del $21^{\circ}$ secolo. La seconda parte è dedicata alla comprensione dell'articolazione tra i NEAB, I 'Asssociação Brasileira de Investigadores Negros" - ABPN e il "Consortium NEABs - CONNEABs", nonché la caratterizzazione dei nuclei. La terza parte è dedicata alla discussione sui contributi dei "Nuclei de Estudos Afro-Brasileiros" alle azioni finalizzate alla 
rieducazione delle relazioni etnico-razziali. Viene evidenziata una serie di frammenti di interviste ad intellettuali neri e neri coinvolti nelle attività del NEAB.

Azioni affermative. Nucleo di studi afro-brasiliani. Formazione scolastica.

Relazioni etnico-razziali.

\section{INTRODUÇÃO}

Os Núcleos de Estudos Afro-Brasileiros tratam-se de uma rede diversa, heterogênea e complexa, inserida em diferentes espaços de ensino, mas especialmente na ambiência universitária, composta por docentes, discentes e técnicos-administrativos, e, por vezes, membros da comunidade externa, tais como, representantes de movimentos sociais, militantes e estudiosos, em que são desenvolvidas atividades de ensino, pesquisa e extensão voltadas para as relações étnico-raciais.

Para além dos conceitos, que são flutuantes, nos interessa compreender o contexto que possibilita a expansão destes núcleos, bem como as potencialidades dos mesmos no que tange a formação crítica de sujeitos, acadêmicos ou não, para a reeducação das relações étnico-raciais, tendo em vista o lugar estratégico e privilegiado de produção de conhecimento onde tais núcleos estão inseridos. Ainda, destacamos a centralidade de intelectuais negras e negros, que têm desempenhado uma função vital de dar vida a estes núcleos, sem desconsiderar a parceria com intelectuais não negras(os) que têm um compromisso com a luta antirracista, como tem ocorrido, com frequência, na organização dos NEABs.

Num primeiro momento, em "Breves considerações sobre o contexto de emergência dos NEABs", destacaremos a conjuntura de expansão dos Núcleos de Estudos Afro-Brasileiros, partindo do pressuposto de que a dilatação das ações afirmativas e cotas sócio raciais na ambiência universitária, o que leva não apenas ao aumento quantitativo de negras(os) neste espaço, mas também a exigência de que as universidades se repensem estruturalmente, torna-se solo fértil de fortalecimento e ampliação dos núcleos. Legislações e editais federais também compõem a cena e serão tratados em um segundo momento.

$\mathrm{Na}$ segunda parte do trabalho, intitulada "O lugar da ABPN e do CONNEABs na consolidação de uma negritude intelectual acadêmica", trataremos sobre a Associação Brasileira de Pesquisadores Negros - ABPN e seu Consórcio de NEABs - CONNEABs, que trarão uma contribuição significativa na constituição e organização dos NEABs em seus espaços institucionais. Trata-se de redes mais amplas, de caráter nacional, que trocarão orientações e darão suporte que devem chegar na base.

Na última parte, "Os Núcleos de Estudos Afro-Brasileiros e a reeducação das relações étnico-raciais", traremos a atuação estratégica dos núcleos na 
reeducação para as relações étnico-raciais. Lançaremos mão de trechos de entrevistas realizadas com intelectuais negras(os), partícipes de Núcleos de Estudos Afro-Brasileiros, inseridos em instituições federais de ensino superior, na região sudeste. As entrevistas são parte da pesquisa de doutorado, em andamento, intitulada "Trajetórias, perspectivas teóricas e práticas da intelectualidade negra partícipe de Núcleos de Estudos Afro-Brasileiros na região sudeste", vinculada ao Programa de Pós Graduação em Educação: Conhecimento e Inclusão Social, da Faculdade de Educação da Universidade Federal de Minas Gerais - FAE/UFMG. Foram realizadas sete entrevistas, sendo que, a parte que lançamos mão neste artigo, compõe o rol de questões relacionadas a presença dos NEABs nas instituições onde estão inseridos.

A importância dos NEABs, e grupos correlatos, vai além da formação para as relações étnico-raciais. Tais núcleos têm se destacado pela luta antirracista, interna e externamente aos seus muros institucionais. A produção de conhecimentos contra hegemônicos, trazendo novas narrativas sobre a história da população afro-brasileira e africana, valorizando as histórias silenciadas e os saberes populares. Para além, os NEABs são espaços de pertencimento, de acolhimento e afetividades para negras e negros que passam a reivindicar um lócus hegemonicamente branco.

\section{Breves considerações sobre o contexto de emergência dos NEABs}

A ampliação numérica dos Núcleos de Estudos Afro-Brasileiros nas universidades públicas ocorreu a partir do início do século XXI. Este aumento não se faz desassociado da implementação de um conjunto de ações e políticas de promoção da igualdade racial. Tais ações trouxeram, material e simbolicamente, uma série de tensões, possibilidades e desafios a partir das novas experiências e perspectivas voltadas para a tentativa de superação de práticas discriminatórias e racistas.

No que tange ao debate em torno das ações afirmativas, são centrais a participação da comitiva brasileira na Conferência de Durban, na África do Sul; a criação da SEPPIR - Secretaria Especial de Políticas de Promoção da Igualdade Racial; a Lei 10.639/03, que altera a Lei de Diretrizes e Bases da Educação Nacional - LDB, ao tornar obrigatório o Ensino da História e Cultura Africana e Afro-Brasileira nas Instituições do Ensino Básico; o Estatuto da Igualdade Racial (Lei 12.288/10); a Lei de Cotas (12.711/12) e a Lei de Cotas em Concursos Públicos (12.990/14). Em seu conjunto, as ações apontadas expressam conquistas históricas advindas das lutas e reivindicações dos movimentos sociais negros e das(os) intelectuais negras(os).

A III Conferência Mundial de Combate ao Racismo, Discriminação Racial, Xenofobia e Intolerância Correlata, popularmente conhecida como Conferência 
de Durban, realizada em 2001, na África do Sul e promovida pela UNESCO, merece destaque, tendo em vista o fato de ter influenciado diretamente na implantação das políticas de ações afirmativas no Brasil, entretanto, a mesma não pode ser pensada deslocada de suas próprias contradições, tendo em vista que tratar sobre questão racial é sempre algo que causa incômodo, uma arena espinhosa, de disputa por poder.

\begin{abstract}
Diferentemente das congêneres do final do Século $X X$, sobre o meio ambiente, os direitos humanos em geral, a população e os direitos da mulher, a primeira conferência do Século $X X I$, inaugurada em 31 de agosto, quase não teve nem mesmo uma sessão de encerramento. Marcada para terminar na tarde de 7 de setembro, seu desfecho protelado ocorreu depois do tempo previsto para sua duração, na tarde do dia 8 . E, para ter seus resultados confirmados pela Assembleia Geral da ONU - ainda assim sem consenso, com dois votos contrários e duas abstenções - foi preciso que a sessão ordinária de 2001 reconvocasse a Assembleia em período extra-regulamentar, no início de 2002. Seus efeitos permanecem, como é sempre natural, dependente da vontade dos responsáveis políticos e "usuários" sociais. (ALVES, 2002, p.199)
\end{abstract}

Sobre Durban, dois aspectos, extremamente relevantes, que não lograram êxito, merecem destaque, na medida em que buscam colocar em discussão no tempo presente a dimensão histórica do racismo associada de forma intrínseca aos colonialismos. Carneiro (2019, p.190) afirma sobre o não reconhecimento da "escravidão africana como crise de lesa humanidade" e a "condenação do passado colonial". Seria o reconhecimento dos males causados aos povos africanos, abrindo brechas para pedidos de reparações. Em relação aos resultados da Conferência, Alves (2002, p.214) sugere que:

\begin{abstract}
Sem dúvida, menos incisivos e menos propícios à abertura de processos indenizatórios do que desejavam países e movimentos sociais, eles são, ainda assim, o que de mais avançado existe na esfera internacional como condenação semijurídica ao colonialismo, à escravidão e ao tráfico de escravos, incriminados, inclusive, como origem de muitos dos sofrimentos presentes, de índios e afrodescendentes.
\end{abstract}

Ainda que repleta de recuos, a Conferência foi bem recebida no Brasil, produzindo resultados positivos na consolidação das ações afirmativas. Carneiro (2019, p.193) ressalta que os reflexos, no Brasil, vão muito além das cotas, que têm ganhado maior destaque. "O que Durban ressalta e advoga é a necessidade de uma intervenção decisiva nas condições de vida das populações historicamente discriminadas". 
A criação da SEPPIR ${ }^{3}$ - Secretaria Especial de Políticas de Promoção da Igualdade Racial, em 2003, foi mais uma iniciativa direcionada para superação do racismo, que na contramão da premissa de tratar a questão racial no Brasil exclusivamente por meio de ações e políticas universais, colocou como eixo estrutural de suas proposições, as particularidades de grupos raciais socialmente marginalizados. A SEPPIR foi uma secretaria criada com o status de ministério e responsável pela proposição de ações de combate ao racismo a partir do Governo Federal, assim como responsável pela articulação entre os ministérios para a implementação de tais ações.

A aprovação da Lei 10.639/03, que torna obrigatório o Ensino da História e Cultura Africana e Afro-Brasileira nas Instituições do Ensino Básico no Brasil, e, posteriormente, a publicação das Diretrizes Curriculares Nacionais para a Educação das Relações Étnico-Raciais e para o Ensino de História e Cultura Africana e Afro-Brasileira (2004), são, de fato, outros atos de força política e de redefinição simbólica na discussão de natureza étnico racial na educação brasileira. Além da obrigatoriedade citada, na legislação em foco, a dimensão simbólica acerca da experiência histórica negro-brasileira também é redimensionada com a inclusão do dia 20 de novembro como 'Dia Nacional da Consciência Negra', buscando-se provocar deslocamentos na memória histórica acerca da agência negra no passado brasileiro.

Sincronicamente, as(os) intelectuais negras(os) foram centrais na aprovação da referida lei, que também produzirá novos significados na agenda de tais sujeitos, na medida em que a obrigatoriedade presente na lei vem produzindo tensões e inquietações de ordem política, pedagógica, historiográfica, entre outras. Tal assertiva pode ser notada na proliferação do debate público, na produção acadêmica e didática sobre a temática em questão.

A Lei 12.288 de 20 de outubro de 2010 institui o Estatuto da Igualdade Racial. Em "Carta do llustríssimo Professor Kabengele Munanga às/aos Colegas, companheiras e companheiros do CNPIR", Munanga fala dos desafios enfrentados para aprovação do Estatuto, bem como dos avanços e recuos que o documento apresenta, mais uma vez indicando, assim como na Conferência de Durban, o quanto as pautas de viés racial ainda causam incômodos.

\footnotetext{
${ }^{3}$ Em maio de 2016, após o Golpe jurídico-parlamentar que culminou no afastamento da Presidenta Dilma Rousseff, houve a extinção do Ministério das Mulheres, da Igualdade Racial, da Juventude e dos Direitos Humanos, assim, a SEPPIR foi incorporada ao Ministério da Justiça e Cidadania. As demandas raciais e de outros grupos socialmente marginalizados aparecem como caso de segurança pública. Assim, justiça e cidadania apareceram "harmonicamente" articuladas em um mesmo Ministério. Na atual administração federal, a Secretaria Nacional de Políticas de Promoção da Igualdade Racial foi deslocada para o Ministério da Mulher, da Família e dos Direitos Humanos (MMFDH). Está sendo associada a pautas tradicionais e conservadoras, muito distantes das lutas dos movimentos negros.
} 
Considerando todas essas dificuldades, penso que o resultado obtido pela aprovação deste estatuto que passou por numerosas negociações acompanhadas de modificações é muito significativo para uma luta feita com armas tão desiguais. Pensem que os africanos resistiram contra a invasão dos colonizadores ocidentais com arcos e flechas ou com fuzis de pólvora obsoletos contra as metralhadoras. Finalmente, perderam e suas terras foram ocupadas porque não houve equilíbrio das relações de força. Mas continuamos a defender nossa dignidade humana que foi coroada pelas independências. Estamos travando novas lutas para construir as nacionalidades, a democracia e o bem estar dos povos. É um longo processo cuja duração não podemos medir, mas que certamente terminará com a vitória. (MUNANGA, 2010, s/p)

As cotas sociais e raciais, um dos principais avanços em direção a redução das desigualdades raciais, foram regulamentadas pelo Decreto $\mathrm{n}^{\circ} 7824$ de 29 de agosto de 2012, que dispõe sobre o ingresso nas universidades federais e nas instituições federais de ensino técnico de nível médio. Assim, a lei garante a reserva de $50 \%$ das vagas, em cursos e turnos, a estudantes oriundos de escolas públicas. A aplicação da lei deveria ocorrer gradualmente, nos quatro anos subsequentes. Em relação a pretos, pardos e índios, a oferta de vagas está inclusa nas cotas e sua porcentagem deverá variar considerando a porcentagem de pretos, pardos e índios no estado, tendo como referência os dados do IBGE - Instituto Brasileiro de Geografia e Estatística. Cabe ressaltar que a implantação do sistema de cotas nas instituições federais de ensino já vinha ocorrendo antes mesmo do Decreto. Em 2012, ano da aprovação da "Lei de Cotas", havia 150 instituições de ensino superior que adotaram as ações afirmativas para ingresso de estudantes negros (SANTOS, 2014).

Em 2014, a Lei 12.990, Lei de Cotas em Concursos Públicos foi aprovada como mais um importante avanço no âmbito das ações afirmativas. Diante da baixa presença de negras(os) nos serviços públicos federais considerando 0 número total de negras(os) no Brasil, a Lei garante a reserva de $20 \%$ das vagas de concursos "no âmbito da administração pública federal, das autarquias, das fundações públicas, das empresas públicas e das sociedades de economia mista controladas pela União".

Os elementos destacados sobre a conjuntura da ampliação das ações e iniciativas de combate ao racismo e à desigualdade racial apontam para a compreensão sobre o processo legal que tem permitido à sociedade brasileira avançar democraticamente no sentido de trazer a cena sujeitos que, historicamente e de forma construída conscientemente, tiveram sua presença extirpada de determinados espaços de poder, tal como a administração pública e o ensino superior.

No âmbito universitário, a maior inserção de negras e negros como docentes e discentes no ensino superior brasileiro, assim como a produção

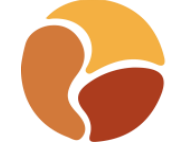


intelectual negra, acadêmica ou não, ganha, potencialmente, maior visibilidade e circulação. A organização política da intelectualidade negra irá se expressar em diferentes espaços, e se configura em importantes ações governamentais e não governamentais de caráter nacional e internacional, eventos, projetos e associações, tais como: o grupo de trabalho Educação e Relações ÉtnicoRaciais da ANPED - Associação Nacional de Pós-graduação em Educação (GT 21) -, criado em 2001; UNIAFRO - programa federal de assistência financeira às instituições de ensino superior federais e estaduais para fomento de ações de formação continuada a professores da educação básica e elaboração de material didático no âmbito do Programa de Ações Afirmativas para a População Negra (2005); Programa Internacional de Bolsas de Pós-graduação da Fundação Ford (2002); ABPN - Associação Brasileira de Pesquisadores Negros; CONNEABS - Consórcio de Núcleos de Estudos Afro-Brasileiros; assim como a ampliação significativa dos NEABs - Núcleos de Estudos Afro-Brasileiros.

As iniciativas apresentadas são centrais para a ampliação, organização e consolidação de uma negritude intelectual acadêmica. Diante da multiplicidade dos grupos e das ações realizadas, para compreendermos a localização dos NEABs e o significado destes núcleos, trataremos brevemente de duas dessas iniciativas que possuem amplitude nacional e, até o momento, permanência temporal, a saber: a ABPN e o CONNEABs.

\section{O lugar da ABPN e do CONNEABs na consolidação de uma negritude intelectual acadêmica}

O primeiro Congresso de Pesquisadores Negros - COPENE ocorreu em 2000, na cidade de Recife. O evento, que é bienal, foi realizado em 2002 na cidade de São Carlos / São Paulo, onde, de acordo com Gomes (2004, p.16), foi aprovada por unanimidade a criação da ABPN - Associação Brasileira de Pesquisadores Negros, "com o objetivo principal de congregar pesquisadores que tratem da questão racial, de maneira direta ou indireta, ou se identifiquem com os problemas que afetam a população negra no Brasil”. Desde então, é a ABPN quem organiza os COPENEs ${ }^{4}$.

\footnotetext{
${ }^{4}$ O I COPENE foi realizado de 22 a 25 de novembro de 2000, em Recife (Pernambuco); o II COPENE ocorreu de 25 a 29 de agosto de 2002, em São Carlos (São Paulo), com tema "De Preto a Afrodescendente: a Pesquisa"; o III COPENE ocorreu de 06 a 10 de setembro de 2004, em São Luís do Maranhão (Maranhão), com tema "Pesquisa Social e Ações Afirmativas para Afrodescendentes"; o IV COPENE ocorreu em Salvador (Bahia), de 13 a 16 de setembro, com tema "O Brasil Negro e suas Africanidades: Produção e Transmissão de Conhecimentos"; o V COPENE ocorreu de 29 de julho a 1ํ de agosto de 2018, em Goiânia (Goiás), com tema "Pensamento Negro e Anti-Racismo: Diferenciações e Percursos"; o VI COPENE ocorreu de 26 a 29 de julho de 2010, na cidade do Rio de Janeiro (Rio de Janeiro), com a temática "AfroDiáspora, Saberes Pós-Coloniais, Poderes e Movimentos Sociais"; o VII COPENE ocorreu em Florianópolis (Santa Catarina), entre 16 e 20 de julho de 2012, com temática "Os desafios da luta antirracista do século XXI"; o VIII COPENE ocorreu no Belém (Pará) de 29 de julho a 02 de

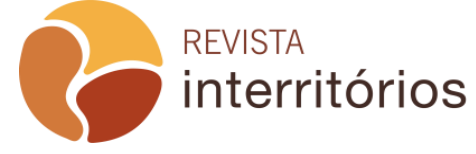

Interritórios | Revista de Educação Universidade Federal de Pernambuco, Caruaru, BRASIL | V.6 N.12 [2020]
} 
Conforme apresentado no site da ABPN, a mesma é uma "associação civil, sem fins lucrativos, filantrópica, assistencial, cultural, científica e independente, tendo por finalidade o ensino, pesquisa e extensão acadêmicocientífica sobre temas de interesse das populações negras do Brasil"5.

A valorização e divulgação do conhecimento produzido por aquelas e aqueles que se colocam política e intelectualmente contra o racismo é uma questão central para a associação que, além de organizar os COPENEs nacionais e regionais, a entidade possui uma revista indexada em diversos diretórios editoriais e classificada como Qualis B e gerencia um banco de teses e dissertações aberto para divulgação, incentivando a leitura e citação de pesquisadoras(es) negras(os), o que ainda é um desafio diante de uma academia branca.

Envolvida com questões para além do mundo acadêmico, a ABPN está representada nos mais diversos fóruns acadêmicos e políticos, tanto no âmbito da sociedade civil quanto no estatal, que tratam da temática racial e igualdade racial, em órgão nacionais e internacionais, incluindo o CNPIR - Conselho Nacional de Promoção da lgualdade Racial e a AINALC - Associação de Investigadores Negros da América Latina e Caribe.

Assim, a ABPN tem se posicionado de forma contundente diante das questões que envolvem a população negra, atuando contra a violação de direitos, mas também lutando por políticas públicas que promovam a igualdade racial, com destaque para o protagonismo diante do debate nacional em torno das ações afirmativas.

Neste mesmo movimento, o Consórcio de NEABs constitui-se vinculado à ABPN, em articulação e trânsito com a ampliação de acadêmicas(os) negras(os) e os movimentos sociais. "O CONNEABs proporciona uma integração de experiências e saberes que se constroem no cotidiano de cada núcleo" (MATTOS; MARQUES, 2016, p.5).

Destarte, ficam em evidência as potencialidades de um campo fértil para a ampliação e fortalecimento dos Núcleos de Estudos Afro-Brasileiros nas universidades públicas, privadas e institutos federais. Sobre os NEABs, Gomes (2010, p.501) afirma:

agosto, com temática "Ações Afirmativas: cidadania e relações étnico-raciais"; o IX COPENE ocorreu de 19 a 23 de julho de 2016, em Dourados (Mato Grosso do Sul), com temática "Novas Fronteiras da Intolerância Racial: Velhas Práticas de Discriminação e Novos Espaços Universo Web"; por fim, o X COPENE ocorreu em Uberlândia (Minas Gerais), de 12 a 17 de outubro de 2018, com temática "(RE) Existência Intelectual Negra e Ancestral". Disponível em: $<$ https://www.abpn.org.br/anais-copenes>. Acesso em: 23 nov. 2018.

${ }^{5}$ Disponível em: https://www.abpn.org.br/quem-somos. Acesso em: 23 nov. 2018. 
Os NEABs são núcleos compostos de pesquisadores e pesquisadoras, na sua maioria negra, que tematizam a diversidade étnico-racial e realizam ações de ensino, pesquisa e extensão voltados para a mesma. Esses núcleos, apesar de nem sempre ocuparem lugares hegemônicos no interior das universidades onde estão localizados, possuem uma atuação que se traduz na produção de um conhecimento politicamente posicionado.

Os NEABs reivindicam outras narrativas e outros saberes em torno da raça, questionando o conhecimento eurocêntrico voltado para a temática, que desumaniza os não brancos, hierarquiza estes sujeitos e rejeitam suas crenças, valores, suas histórias. É ainda um espaço de luta e resistência contra o racismo e a discriminação.

Neste mesmo sentido, Mattos e Marques (2016, p.5) afirmam sobre os objetivos dos núcleos, que buscam "promover o fortalecimento da luta e resistência, valorizar a população negra, garantir e ampliar direitos por meio de iniciativas acadêmicas que orientam a formulação de políticas voltadas para a erradicação do racismo e da discriminação".

Os NEABs têm se consolidado enquanto lócus privilegiado na produção de conhecimentos contra hegemônicos, dialogando com novas concepções teóricas, que questionam uma leitura binária e hierárquica da realidade social. No artigo "Justiça Cognitiva: a produção bibliográfica dos NEABs e grupos correlatos", Shirley Miranda et al. (2018) tratam sobre o protagonismo dos núcleos e grupos correlatos na construção de saberes em torno da discussão racial, saberes esses que buscam uma inflexão epistemológica que questiona a construção de conhecimentos eurocêntricos em torno da raça.

A atuação dos NEABs, que dá sustentação a produção das(os) intelectuais negras(os), sinaliza para uma significativa contribuição no enfrentamento de discriminações de forma mais ampla e, no ambiente acadêmico, de forma mais assertiva, em contraposição ao epistemicídio. A prática epistemicida, segundo Sueli Carneiro (2005), trata-se de uma negação das formas de conhecimento produzidas por sujeitos negros. Diante disso, podemos considerar que o enfrentamento de tais práticas pode contribuir para o alargamento do horizonte epistêmico relativo à produção de conhecimento no interior da universidade brasileira, assim como combater a longa tradição colonial de valorização da monocultura de conhecimentos considerados legítimos, orientados unicamente por parâmetros eurocentrados.

Os NEABs, enquanto espaços de formação e de construção de conhecimento sobre a questão étnico-racial, apresentam-se como campos de diálogo, de fortalecimento teórico, mas também de pertencimento e solidariedade diante dos comuns ataques e assédios experenciados por aqueles 
que se colocam para os temas acadêmicos periféricos, e cujos corpos ainda carregam representações inferiorizantes.

A não institucionalização de muitos NEABs é uma dimensão que ainda precisamos avançar, já que se trata, na grande maioria, de núcleos inseridos no interior das instituições acadêmicas públicas e a legitimidade institucional é fundamental para o avanço das pautas antirracistas, para além de questões de ordem burocrática. De acordo com Santana e Coelho ${ }^{6}$ (2014, p.7), a institucionalização:

Em primeiro lugar, ela garante existência jurídica aos Núcleos, corroborando sua ligação com os espaços institucionais em que se inserem. Em segundo lugar, ela representa o reconhecimento das mesmas instituições nas demandas incorporadas pelos NEABs. Em terceiro lugar, ela faculta a ação política dos grupos a partir de sua caracterização como instâncias oficiais, garantindo a legitimidade de demandas por espaço físico, equipamentos, pessoal especializado etc.

Guardadas as particularidades dos diferentes NEABs, inseridos em diferentes espaços ocupacionais, percebemos uma frágil institucionalização desses núcleos no arranjo organizacional das universidades. Se por um lado, a situação de incipiência institucional possibilita uma relativa autonomia para a atuação de tais grupos, por outro, sinaliza para um certo desinteresse em torno das questões discutidas pelos mesmos, ou um temor sobre os potenciais deslocamentos que a emergência da presença dos sujeitos participantes dos NEABs e os conhecimentos produzidos em tais espaços podem tensionar a ambiência universitária posta até o momento. Neste sentido, a pouca incidência da institucionalização dos NEABs pode ser lida como parte das ações que tentam sabotar as estratégias culturais racialmente orientadas que são capazes de fazer diferença, tal como aponta Hall (2006). De acordo com o autor:

Já as estratégias culturais capazes de fazer diferença são o que me interessa - aquelas capazes de efetuar diferenças e de deslocar as disposições do poder. Reconheço que os espaços "conquistados" para a diferença são poucos e dispersos, e cuidadosamente policiados e regulados. Acredito que sejam limitados. Sei que eles são absurdamente subfinanciados [...] (HALL, 2006, p. 321)

\footnotetext{
${ }^{6}$ Entre os anos de 2012 e 2014, Santana e Coelho (2014) realizaram um levantamento, através de email, dos NEABs em Instituições de Ensino Superior de todo o país. Noventa e cinco NEABs responderam a solicitação, sendo desses - 32 da região sudeste, 25 da região nordeste, 21 da região sul, 9 da região centro-oeste e 8 da região norte. Além disso, identificou-se que 55 estão vinculados às instituições públicas federais, 26 às públicas estaduais, 12 às privadas e 2 às públicas municipais.
} 
Não devemos desconsiderar que há na universidade um processo, historicamente construído, que é hierárquico e que busca reforçar a dominação e exploração de uma elite branca, machista, heteronormativa, que não deseja abrir mão de seus privilégios. O pensamento científico eurocentrado, que não questiona tais hierarquias, e muitas vezes tem servido como estrutura para reforçá-las, tem centralidade nesta universidade. Entretanto, compreendemos que essa não seja uma relação retilínea e intransponível, sendo que, os NEABs constituem espaços capazes de causar fissuras nas relações historicamente instituídas de dominação e exploração, o que já vem ocorrendo em muitas universidades do país. Neste sentido, é salutar observamos as potencialidades já identificadas na atuação dos NEABs.

\section{Os núcleos de estudos Afro-brasileiros e a reeducação das relações étnico-raciais}

Uma das dimensões central, que legitima a existência dos NEABs, relaciona-se à reeducação das relações étnico-raciais. Tal dimensão se faz presente tanto em documentos normativos quanto nas atividades dos núcleos. No âmbito das atividades, identificamos tanto a formação entre os discentes da graduação, participantes da comunidade externa, e também entre professores da educação básica.

Quanto aos documentos normativos, ressaltamos o Plano Nacional de Implementação das Diretrizes Curriculares Nacionais para Educação das Relações Étnico-Raciais e para o Ensino de História e Cultura Afro-Brasileira e Africana (BRASIL, 2009). Tal documento aponta que as ações a serem desenvolvidas pelos NEABs e grupos correlatos, devem passar por um rol bastante diverso de iniciativas, tais como a formação de professores e graduandos na área da educação, a elaboração de materiais didáticos, bem como o desenvolvimento e divulgação de estudos e pesquisas voltadas para a temática étnico-racial. Merecem destaque, ainda:

A participação nos Editais da UNIAFRO ${ }^{7}$ como proponente de cursos de formação em educação para as relações étnicoraciais para docentes da Rede Pública de Ensino em todo o Brasil, a participação na pesquisa nacional realizada no ano de 2009 sobre "Práticas Pedagógicas de Trabalho com Relações Étnico-Raciais na Escola na Perspectiva da Lei N. 10.639/2003". (FERREIRA; COELHO, 2019, p. 220)

\footnotetext{
${ }^{7}$ Assinatura do Acordo de Cooperação entre MEC e NEABs no ano de 2005. Publicado no Diário Oficial da União dia 29/04/2005. Disponível em:

http://portal.mec.gov.br/sesu/arquivos/pdf/uniafroedital.pdf. Acesso em: 10 jun. 2018.
} 
É interessante percebermos que as ações anteriormente apontadas, que compõem algumas das prescrições legais acerca da atuação dos NEABs e grupos correlatos, indicam que foram pensadas enquanto uma possibilidade orgânica e articulada de construção de uma espécie de rede de grupos e iniciativas voltadas para uma educação comprometida com uma perspectiva antirracista, na qual, o princípio de reeducar para o convívio na esfera pública, não organizado por lógicas raciais desiguais e discriminatórias, seja central.

Nesta rede, estariam presentes ações de formação docente, tanto inicial para os graduandos em licenciatura, como a formação continuada de professores já inseridos no contexto da Educação Básica; propostas de elaboração de materiais didáticos desenvolvidos para mediação pedagógica em contexto escolar com a finalidade antirracista; iniciativas à produção de pesquisas que ampliariam os conhecimentos e percepções sobre questões relevantes para experiência histórica das populações negras, tanto no que tange ao seu passado, presente e futuro; e projetos de divulgação de tais estudos e pesquisas, o que poderia ser uma potente intervenção de popularização de parte do conhecimento produzido no interior da universidade para além dos seus domínios.

O desenvolvimento de materiais didáticos e pedagógicos elaborados com finalidades claramente antirracistas, assim como que trouxessem em sua centralidade a finalidade educativa da reeducação étnico-racial, certamente, é e pode ser uma iniciativa positiva de enfrentamento ao racismo no contexto educacional protagonizado pelos NEABs. Não são novos, nem poucos, os estudos que diagnosticam como as representações acerca dos negros e negras circulam de forma simplificada, estigmatiza e estereotipada em materiais didáticos de diferentes disciplinas escolares e em diversas etapas da escolarização (FILHO, 2005; NASCIMENTO, 2005; OLIVEIRA, 2000; ROSEMBERG, 2003; SILVA, 2004).

Muito embora haja mudanças no contexto pós-Lei 10.639/03, é importante evidenciar que os conglomerados transnacionais do mercado editorial que dominam a produção, circulação e consumo de livros didáticos no Brasil (CASSIANO, 2013), não produzem materiais didáticos diretamente voltados para a construção de uma reeducação das relações étnico-raciais, mas sim materiais didáticos de diferentes componente curriculares que cumpram as prescrições de participação nos editais do Programa Nacional do Livro Didático (PNLD), que incluem a Lei 10.639/03 e legislação correlata.

A referida legislação, em contraposição e em combate à produção e circulação de representações subalternizadas, assim como o apagamento histórico de indivíduos e grupos de pertencimento étnico-racial de origem africana, parte do pressuposto da necessidade de reposicionamento das(os) 
negras(os) na memória social. Neste sentido, a produção da intelectualidade que compõe os NEABs poderia se popularizada no contexto escolar por meio da difusão de materiais pedagógicos comprometidos com uma educação antirracista.

A opção de combate ao racismo por meio da reeducação das relações étnico-raciais configura-se como uma estratégia que considera em sua centralidade a dimensão relacional e de aprendizagem do racismo. A noção de educação das relações étnico-raciais é entendida como o conjunto de práticas, tanto simbólicas, quanto materiais, que se sedimentaram cultural e historicamente, de tratamento entre sujeitos de pertencimentos raciais e étnicos diversos. Desta forma, entende-se que o racismo é construído por meio de relações sociais e de poder desiguais e assimétricas e que a naturalização de tais relações ocorre por meio de práticas e representações que "educam" os sujeitos para o desenvolvimento de ações e pensamentos racialmente orientados.

Partindo deste pressuposto, para o desenvolvimento de uma pedagogia antirracista, faz-se necessário a construção de proposições orientadas para a reeducação das relações étnico-raciais de forma positivada no que tange ao respeito à diversidade dos grupos humanos em seus múltiplos pertencimentos, tais como os raciais e étnicos, sendo essa, uma das potencialidades dos Núcleos de Estudos Afro-brasileiros.

Com o objetivo de explicitar possibilidades dos NEABs na discussão em questão, dialogaremos, a seguir, com alguns fragmentos de entrevistas realizadas a partir da tese de doutorado, em andamento, intitulada "Trajetórias, perspectivas teóricas e práticas da intelectualidade negra partícipe de Núcleos de Estudos Afro-Brasileiros na região sudeste". Foram realizadas entrevistas com sete intelectuais negras(os) partícipes de cinco Núcleos de Estudos AfroBrasileiros, vinculados às seguintes instituições: Universidade Federal de Ouro Preto - UFOP, Universidade Federal de Minas Gerais - UFMG, Universidade Federal Rural do Rio de Janeiro - UFRRJ, Universidade Federal de São Carlos - UFSCAR, e Universidade Federal do Espírito Santo - UFES. Os nomes das(os) entrevistadas(os) serão preservados, utilizaremos apenas números para identificar os sujeitos. Trata-se de um conjunto de excertos com falas de diversas(os) intelectuais negras e negros participantes de NEABs. As entrevistas reafirmam a ideia trabalhada no decorrer deste artigo dos NEABs enquanto espaços propositivos de ações organizadas para a reeducação das relações étnico-raciais.

$\mathrm{Na}$ compreensão da intelectualidade negra atuante nos NEABs, há o entendimento sobre a necessidade de combate ao racismo e do desenvolvimento de ações orientadas para a reeducação das relações étnico- 
raciais em consonância com o tripé estruturante do ensino superior público brasileiro, ou seja, ações que contemplem o ensino, a pesquisa e a extensão.

Então, o NEAB hoje é uma rede complexa, de uma certa intelectualidade que está produzindo conhecimento, trazendo uma questão étnica e racial de diferentes formas e dimensões, tanto no campo do ensino, da pesquisa, da extensão, e principalmente na questão da formação. (ENTREVISTA 04, set. 2019)

A construção de uma educação antirracista passa pela compreensão das relações de opressão que estruturam nossa sociedade. Neste sentido, o entendimento sobre o papel das instituições de ensino, como as universidades e os institutos federais, afasta-se de uma lógica ancorada em uma razão instrumental e em sentidos formativos tecnicistas, bem como de parâmetros nivelados pelos ditames do mercado. Ao contrário, os pilares formativos voltamse para uma concepção da função social do conhecimento e sua produção, que incluem a formação de quadros profissionais aptos a atuação em seus campos profissionais, com sensibilidades acerca das questões socialmente vivas e relevantes em seu tempo presente, como é o caso do enfrentamento ao racismo. Tal entendimento pode ser percebido na fala reproduzida a seguir:

São importantes lugares de formação, e formação principalmente para mim, que eu acredito muito, formação na graduação, ou de ensino médio, dependendo, se o NEAB for no IFES, mas essa formação mais de base, acho que eles têm principalmente uma função educativa (...). (ENTREVISTA 01, nov. 2019)

Neste sentido, os NEABs contribuem para avançarmos na construção de propostas pedagógicas para uma educação antirracista, produzindo conhecimentos que contribuem para a superação da "subalternização dos saberes produzidos pela comunidade negra, a presença dos estereótipos raciais nos manuais didáticos, a estigmatização do negro, os apelidos pejorativos e a versão pedagógica do mito da democracia racial" (GOMES, 2007, p.104).

A formação continuada de professores, incluindo a participação dos NEABs no UNIAFRO, mas indo além deste programa, é uma das ações voltadas para a reeducação das relações étnico-raciais promovidas. A menção a essa modalidade de formação é recorrentemente rememorada pela intelectualidade negra entrevistada. "Se a gente for quantificar o número de cursos, de formações de professores, como a gente é muito engajado na transformação, às vezes a gente não dá conta de fazer um balanço do que a gente fez(...)" (ENTREVISTA 03, ago. 2019). 
A constância de iniciativas direcionadas para formação de professores que estão em atividade na educação básica, e que adquiriram sua formação inicial como docentes em momento anterior ao advento da obrigatoriedade do ensino da história e cultura africana e afro-brasileira, sinaliza para 0 compromisso permanente por parte dos NEABs da ampliação do acesso a uma educação comprometida com a reeducação das relações étnico-raciais.

A recorrência à atuação na formação de professores aponta para um aspecto importante da luta antirracista por meio da reeducação das relações étnico-raciais. $\mathrm{Na}$ formação de professores, seja ela inicial ou continuada, é considerada pela legislação correlata a obrigatoriedade do ensino da história e cultura africana e afro-brasileira como caminho fundamental para o combate ao racismo e, em tal combate, aos NEABs é sugerido protagonismo. Neste sentido, as entrevistas apontam para consonância com a legislação em questão e, além disso, demostram como parte da intelectualidade envolvida em tais grupos acredita no poder da educação formal, no trabalho de reeducar para convívio não-hierarquizado por critérios racializados.

Nós montamos um núcleo com várias atividades, mas principalmente, a formação de professor, já em abril, fizemos formação para 200 pessoas (...). Quando eu assumi o NEAB, eu fui trazendo toda essa capacitação de qualificação dos professores. (...) Os grandes seminários que o NEAB fez, fazia parceria com a secretaria de estado da educação, e as parcerias sempre eram assim (...). (ENTREVISTA 07, dez. 2019).

Consideramos que tais formações funcionam como uma teia, indo para além do espaço universitário, chagando até familiares, amigos e outros sujeitos com os quais nos relacionamos, no mundo on e off line. Assim, a luta antirracista vai se alastrando e se intensificando.

Fizemos uma coisa importante, o primeiro curso sobre negro e educação na cidade de São Carlos, dirigido a professores da rede, nós tivemos acho que 74 inscritos, ninguém faltou. (...) $E$ fizemos, claro, seminários com estudantes, e fizemos também um encontro com mães, mães no clube negro, no mês de maio. (...) a gente trabalhou muito na formação de professores na questão das relações étnico-raciais, com os estudantes. (ENTREVISTA 06, mar. 2020).

Outro aspecto a ser evidenciado no que tange a compreensão dos NEABs como espaços de formação antirracista relaciona-se a possibilidade de empoderamento e formação de novos quadros para o enfrentamento do racismo na sociedade brasileira. Muito embora a luta antirracista historicamente vem sendo desenvolvida em diferentes frentes dos movimentos negros (ALBERTI; PEREIRA, 2007; DOMINGUES, 2007), assim como por meio de ações 
individuais e dispersas, a expansão dos NEABs ocorre vinculada ao contexto de ações afirmativas e, ao mesmo tempo, os NEABs também são centrais na implementação destas ações, através da participação em comissões, conselhos, estudos, criação de documentos, etc., tanto em âmbito federal quanto local. Neste sentido, a formação de grupos de estudos e pesquisas no interior dos núcleos pode ser compreendido como uma possibilidade de, simultaneamente, colocar em relevo releituras das experiências históricas negras no Brasil, reposicionando nosso lugar na memória e história brasileira, e formar novos pesquisadores e novas pesquisadoras orientadas(os) por epistemologias contrastivas à monocultura do conhecimento que sustenta a colonialidade do saber.

Tal assertiva aparece evidenciada de diferentes formas. Os grupos de pesquisa também são pensados enquanto espaços de formação de estudantes. "(...) grupo de pesquisa, ele vem justamente para eu garantir formações aos estudantes, que eu acho que é uma função muito importante dos núcleos, e de nós mesmo às vezes, de forma individual, que é fazer a formação dos estudantes" (ENTREVISTA 01, nov. 2019).

A experiência de hooks (2017), compartilhada no livro "Ensinando a transgredir", nos diz da potência da educação antirracista, apontando o aprendizado como um ato político e revolucionário. "Aprendemos desde cedo que nossa devoção ao estudo, à vida do intelecto, era um ato contra hegemônico, um modo fundamental de resistir a todas as estratégias brancas de colonização racista" (HOOKS, 2017, p.10). A autora descreve o prazer que sentia ao ser transformada por novas ideias, e nos indica caminhos possíveis, que não são de silenciamento, mas de potencialização.

Por fim, é importante ressaltar que não foi objetivo deste artigo uniformizar os Núcleos de Estudos Afro-Brasileiros e suas trajetórias. São espaços diversos em suas ações, organização interna, meios de difusão de suas produções, etc., que também passam por múltiplos momentos e diferentes experiências. Entretanto, a dimensão reeducativa voltada para as relações étnico-raciais relaciona-se diretamente com a razão estrutural dos núcleos e tem sido algo recorrente. Caminhos frutíferos têm sido trilhados, sendo este um espaço importante, que compõe um universo de forças que se articulam pela luta antirracista, e que exige esforços nos diferentes espaços sociais que compõem a nossa sociedade.

\section{CONSIDERAÇÕES FINAIS}

A atuação dos Núcleos de Estudos Afro-brasileiros é ainda uma temática investigativa pouco desenvolvida, contudo tais espaços localizam-se no interior da universidade de forma complexa. Como apontado anteriormente, se por um 
lado, os NEABs estão localizados de forma frágil e pouco institucionalizada na trama burocrática das instituições do ensino superior público brasileiro, por outro lado, uma ampla variedade de ações são gestadas e realizadas em tais espaços. Indubitavelmente, a necessidade da institucionalização dos núcleos faz-se presente, uma vez que essa ação poderia facilitar o acesso aos recursos e à ampliação da legitimidade no interior das universidades. Contudo, é importante ressaltar que a institucionalização não pode significar o aprisionamento ou a limitação dos NEABs a um formato fechado de núcleo. Compreendemos que uma das potencialidades dos NEABs se encontra exatamente na diversidade de formas pelas quais se organizam e criam suas ações, modulando suas iniciativas a partir da organicidade de seus componentes e das questões colocadas pelas lutas antirracistas impostas pela realidade.

O papel estratégico dos NEABs para o fomento de iniciativas voltadas para proposição de ações orientadas para a reeducação das relações étnicoraciais é um ponto que consideramos fundamental resgatarmos. Considerando que a implementação e a efetivação da obrigatoriedade do ensino da história e cultura africana e afro-brasileira encontra-se ainda em marcha.

Além da guinada conservadora e privatista que ampliou sua efetividade política e ganhou visibilidade na vida pública brasileira, especialmente, após o Golpe jurídico-parlamentar de 2015, a real efetivação da Lei 10.639/03 apresenta dificuldades em decorrência dos limites e dificuldades estruturais presentes no sistema educacional brasileiro, assim como a persistência histórica de perspectivas racistas no contexto educacional.

Neste contexto, os NEABs reafirmam sua relevância como uma das possibilidades de contraponto democrático na produção e divulgação de conhecimento socialmente relevante e eticamente orientado. Como dito anteriormente, a significância dos NEABs supera a formação voltada para docentes no que tange a temática da educação das relações étnico-raciais. Estes coletivos de pesquisadoras(es), majoritariamente, negras e negros, apontam, por meio das iniciativas já realizadas, para uma real possibilidade de trocas de saberes e conhecimentos entre a universidades e as comunidades externas a tal instituição, assim como uma oportunidade de construção de contrapontos epistemológicos à produção de conhecimentos hegemônicos.

\section{REFERÊNCIAS}

ALBERTI, Verena; PEREIRA, Amilcar. (Org.). Histórias do movimento negro no Brasil: depoimentos ao Cpdoc. Rio de Janeiro: Pallas/Cpdoc-FGV, 2007.

ALVES, J. A. Lindgren. A Conferência de Durban contra o Racismo e a responsabilidade de todos. Rev. bras. polít. int. [online], vol.45, no 02, p.198-223, 
2002. Disponível em: http://dx.doi.org/10.1590/S0034-73292002000200009. Acesso em: 23 mar. 2017.

BRASIL. Presidência da República. Lei no 12.990, de 09 de junho de 2014. Dispõe sobre a reserva aos negros $20 \%$ (vinte por cento) das vagas oferecidas nos concursos públicos para provimento de cargos efetivos e empregos públicos no âmbito da administração pública federal, das autarquias, das fundações públicas, das empresas públicas e das sociedades de economia mista controladas pela União. Brasília-DF, 09 jun. 2014. Disponível em: http://www.planalto.gov.br/CCIVIL_03/_Ato20112014/2014/Lei/L12990.htm. Acesso em: 04 dez. 2018.

BRASIL. Decreto no 7.824, de 11 de outubro de 2012. Regulamenta a Lei no 12.711, de 29 de agosto de 2012, que dispõe sobre o ingresso nas universidades federais e nas instituições federais de ensino técnico de nível médio. Brasília-DF,11 out. 2012. Disponível em: http://www.planalto.gov.br/ccivil_03/_ato2011-

2014/2012/decreto/d7824.htm. Acesso em: 04 dez. 2018.

BRASIL. Lei 12.711, de 29 de agosto de 2012. Dispõe sobre o ingresso nas universidades federais e nas instituições federais de ensino técnico de nível médio e dá outras providências. Brasília-DF, 29 ago. 2012. Disponível em: http://www.planalto.gov.br/ccivil_03/_ato2011-2014/2012/lei/l12711.htm. Acesso em: 04 dez. 2018.

BRASIL. Lei no 12.288, de 20 de julho de 2010. Institui o Estatuto da Igualdade Racial. Brasília-DF, 20 jul. 2010. Disponível em:

http://www.planalto.gov.br/ccivil_03/_Ato2007-2010/2010/Lei/L12288.htm. Acesso em: 04 dez. 2018.

BRASIL. Ministério da Educação / Secretaria de Educação Continuada, Alfabetização e Diversidade. Diretrizes Curriculares Nacionais para a Educação das Relações Étnico-Raciais e para o Ensino de História e Cultura Afro-Brasileira e Africana. Brasília, 2004. Disponível em: http://inep.gov.br/informacao-da-publicacao. Acesso em: 04 dez. 2018.

BRASIL. Plano Nacional de Implementação das Diretrizes Curriculares Nacionais para a Educação das Relações Etnicorraciais e para o Ensino de História e Cultura Afrobrasileira e Africana. 2009. Disponível em: http://portal.mec.gov.br/index.php?. Acesso em: 04 de ago. 2016.

BRASIL. Presidência da República. Lei no 10.639, de 09 de janeiro de 2003. Altera a Lei no 9.394, de 20 de dezembro de 1996, que estabelece as diretrizes e bases da educação nacional, para incluir no currículo oficial da Rede de Ensino a obrigatoriedade da temática "História e Cultura Afro-Brasileira", e dá outras providências. Brasília-DF, 09 jan. 2003. Disponível em: http://www.planalto.gov.br/ccivil_03/LEIS/2003/L10.639.htm. Acesso em: 04 dez. 2018.

CARNEIRO, Sueli. A batalha de Durban. Escritos de uma vida. Sueli Carneiro. São Paulo: Pólen Livros, p. 185-194, 2019.

CARNEIRO, Sueli A construção do outro como não ser como fundamento do ser. [Tese de doutorado]. São Paulo: Faculdade de Educação da Universidade de São Paulo, 2005, p.96. 
CASSIANO, Clélia Cristina de F. O mercado do livro didático no Brasil do século XXI: a entrada do capital espanhol na educação nacional. São Paulo: Edusp, 2013.

DOMINGUES, Petrônio. Movimento Negro Brasileiro: alguns apontamentos históricos. Tempo (UFF), Niteroi (RJ), vol.23, 2007.

FERREIRA, Anne de Matos Souza. COELHO, Wilma de Nazaré Baía. Ações dos Núcleos de Estudos Afro-Brasileiros (NEABS) institucionalizados dos Institutos Federais de Educação, Ciência e Tecnologia (IFETS) no período de 2006 a 2017. Revista Exitus, Santarém/PA, Vol.9, №5, p.215-242, Edição Especial, 2019.

FILHO, João Bernardo da Silva. Os discursos verbais e iconográficos sobre Negros em Livros Didáticos de História. [Dissertação de Mestrado]. Belo Horizonte: Faculdade de Educação, Universidade Federal de Minas Gerais, 2005.

GOMES, Nilma Lino. Intelectuais negros e produção do conhecimento: algumas reflexões sobre a realidade brasileira. Epistemologias do sul / Boaventura de Sousa Santos, Maria Paula Meneses [orgs.]. - São Paulo: Cortez, 2010.

GOMES, Nilma Lino. Diversidade étnico-racial e educação no contexto brasileiro: algumas reflexões. Um olhar além das fronteiras: educação e relações raciais. Nilma Lino Gomes (Org.). - Belo Horizonte: Autêntica, p.97-110, 2007.

GOMES, Nilma Lino. Levantamento bibliográfico sobre relações raciais e educação: uma contribuição aos pesquisadores e pesquisadoras da área. In: Bibliografia básica sobre relações raciais e educação. Cláudia Miranda, Francisco Lopes de Aguiar e Maria Clara di Pierro [Orgs.] - Rio de Janeiro: DP\&A, 2004.

HALL, Stuart. Que "negro" é esse na cultura negra? In: Da diáspora: identidades e mediações culturais. Belo Horizonte/Brasília: Editora UFMG/Unesco, p.317-330, 2006.

HOOKS, bell. Ensinando a transgredir: a educação como prática da liberdade. 2.ed. - São Paulo: Editora WMF Martins Fontes, 2017.

MATTOS, Wilson. MARQUES, Eugênia Portela de Siqueira. Apresentação. In: Educação, relações étnico-raciais e resistência: as experiências dos Núcleos de Estudos Afro-brasileiros e Indígenas no Brasil. Eugenia Portela Siqueira Marques, Wilker Solidade da Silva [Orgs.] - Assis: Triunfal Gráfica e Editora, 2016.

MIRANDA, Shirley. Et al. Justiça cognitiva: a produção bibliográfica dos NEABs e grupos correlatos. In: Educação das relações étnico-raciais: o estado da arte. Paulo Vinícius Baptista da Silva, Kátia Regis, Shirley Aparecida de Miranda [Orgs.] Curitiba: NEAB-UFPR e ABPN, 2018.

MUNANGA, Kabengele. Carta do Ilustríssimo Professor Kabengele Munanga às/aos Colegas, companheiras e companheiros do CNPIR. Geledes. 06 dez. 2010. Disponível em: https://www.geledes.org.br/carta-ilustrissimo-prof-kabengele-munangaasaos-colegas-companheiras-e-companheiros-cnpir/. Acesso em: 10 nov. 2018.

NASCIMENTO, Álvaro Pereira. Qual a condição social dos negros no Brasil no fim da escravidão? O pós-abolição no ensino de História. In: SALGUEIRO, Maria Aparecida Andrade (org.). A República e a questão do negro no Brasil. Rio de Janeiro: Museu da República, p. 11-26, 2005.

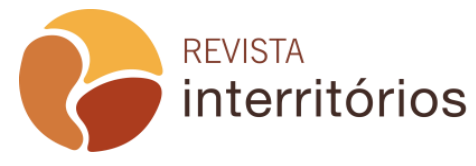


OLIVEIRA, Marco A. de. O negro no ensino de história: temas e representações. [Dissertação de Mestrado]. São Paulo: Faculdade de Educação, Universidade de São Paulo, 2000.

ROSEMBERG, Fúlvia. Racismo em livros didáticos brasileiros e seu combate: uma revisão da literatura. Educação e Pesquisa. São Paulo, v.29, n.1, p.125- 146, 2003.

SANTANA, Moisés. COELHO, Wilma. Apresentação: Consórcio dos Núcleos de Estudos Afro-Brasileiros (CONNEABs). In: 0 enfrentamento do racismo e preconceito no Brasil: a experiência dos NEABs. Moisés Santana, Wilma de Nazaré Baía Coelho, Paulino Cardoso [Orgs.] - Itajaí, SC: Casa Aberta, 2014.

SANTOS, Sales Augusto dos. Ações Afirmativas nos Governos FHC e Lula: um Balanço. Revista do Programa de Pós-Graduação em Sociologia da Universidade Federal de Sergipe, n. 24, p. 37-84, jan/jun. 2014.

SILVA, Ana Célia da. A Discriminação do negro no livro didático. 2.ed. Salvador: EDUFBA, 2004. 